Revista de

Contabilidade e

Organizações

www.rco.usp.br
DOI: http://dx.doi.org/10.11606/issn.1982-6486.rco.2018.148149

Journal of

Accounting and

Organizations

\title{
A influência da família tem algum efeito? Análise da remuneração dos executivos das empresas familiares e não familiares
}

Does the influence of the family have any effect? Analysis of the remuneration of executives of family and nonfamily companies

Thaisa Renata Santosa; Júlio Orestes Silva ${ }^{a}$

${ }^{a}$ Universidade Federal de Goiás

\section{Palavras-chave}

Remuneração Executiva.

Empresas familiares.

Remuneração variável.

Remuneração total.

\section{Resumo}

Este estudo investiga se a presença da família na empresa influencia a remuneração executiva, cujo objetivo pode estar voltado para a preservação dos valores da família. Os resultados obtidos, a partir da análise dos dados de 110 empresas brasileiras de capital aberto, durante 2010 a 2016, mostram que a influência familiar, captada pela presença da família na empresa, possuí relação direta com a remuneração fornecida aos executivos. Tal resultado indica que tanto a remuneração total quanto a remuneração variável de executivos são menores nas empresas familiares, e uma menor proporção da remuneração variável em seus sistemas de incentivos se comparadas às empresas não familiares brasileiras.
Keywords

Executive Remuneration.

Family business.

Variable salary.

Total remuneration.
Informações do Artigo

Recebido: 13 de julho de 2018

Aceito: 18 de dezembro de 2018

Publicado: 24 de dezembro de 2018

\begin{abstract}
This study investigates whether the presence of the family in the company influences the remuneration provided to executives of Brazilian family companies in comparison to non-family businesses. In family businesses, the objectives may are focused on preserving family values, and the attribution of compensation to executives tends to be differentiated from other non-family businesses. The results, obtained from the analyses of 110 Brazilian public companies from 2010 to 2016, show that the family influence, captured by the presence of the family in the company, has a direct relation with the remuneration provided to executives. This result suggests that total remuneration and variable remuneration are lower in family firms, if compared to non-Brazilian companies.
\end{abstract}

\section{Implicações práticas}

Executivos, controllers de recursos humanos e especialistas em avaliação de desempenho e remuneração executiva podem estar interessados em considerar o efeito que a presença da família no controle e gestão de empresas familiares podem gerar na remuneração executiva. Os incentivos a executivos em empresas familiares podem ser menos intensos em remuneração pecuniária. por isso este nem sempre será o principal elemento para alinhamento de interesses, gerando diferentes desenhos e estruturas de avaliação de desempenho.

Copyright (C) 2018 FEA-RP/USP. Todos os direitos reservados

\section{INTRODUÇÃO}

A relação contratual possui como premissa que o principal delega à outra pessoa (agente) a execução de um serviço que implique na delegação de algum poder de decisão (Jensen \& Meckling, 1976). Diante disso, para acompanhar, monitorar e alinhar interesses, o principal pode promover o controle e tentar reduzir as atividades irregulares do agente (Holmstron \& Milgrom, 1991; Jensen \& Meckling, 1976; Wiseman \& Gomez-Mejia, 1988).

Autor Correspondente: Tel. (62) 3521-1390

E-mail: thaisarenatax10@gmail.com (T. R. Santos); orestesj@gmail.com (J. O. Silva)

Universidade Federal de Goiás. Avenida Esperança s/n, Câmpus Samambaia - Goiânia/GO - 74690-900, Brasil. 
Assim, para diminuir os problemas de agência é necessário buscar um contrato ideal entre gestores e acionistas, para que a satisfação de ambos e seus objetivos sejam alcançados (Jensen \& Murphy, 1990). Contudo, a presença da família, tanto no controle quanto entre os executivos, pode introduzir objetivos adicionais à maximização de resultados econômicos.

Caracterizada como uma relação de agência, a remuneração dos executivos é considerada um instrumento que permite mitigar os problemas entre executivos e proprietários por meio do alinhamento de interesses (Murphy, 2012). A remuneração pode ser definida como o valor monetário resultante da prestação fornecida pelo trabalhador com vínculo contratual (Schwartz, 1996), com o propósito de alinhar interesses, alocar esforços e alcançar os objetivos pelos quais são responsáveis (Beuren, Silva \& Mazzioni, 2014; Silva, 2015).

As características que diferenciam uma empresa familiar de uma empresa não familiar são: a origem da empresa, a história da família fundadora, objetivos e planos, que são mantidos de acordo com as perspectivas dos membros familiares, para a preservação da riqueza socioemocional e continuidade da organização (Memili, Misra, Chang \& Chisman, 2013; Silva, 2015; Gomez-Mejia, Haynes, Núñez-Nickel, Jacobson \& MoyanoFuentes, 2007). Uma vez que a influência da família perpassa os objetivos organizacionais, ela molda os valores e objetivos da empresa inserindo a manutenção da riqueza da própria família entre eles (Silva, 2015). Assim, como empresas familiares possuem características predominantes e peculiares, marcadas pelo envolvimento da família no controle, propriedade e gestão (Mazzi, 2011), a remuneração dos executivos pode ter diferentes características e diferente papel nestas empresas (Speckbacher e Wentges, 2012).

No Brasil, ainda existem poucos estudos sobre este tema, pois o acesso aos dados sobre a remuneração dos executivos nas empresas brasileiras era restrito, ou inexistente. Apenas a partir 2009 algumas informações passaram a ser de divulgação obrigatória (Silva, 2010). Diante disso, o tema da remuneração de executivos tem ganhado cada vez mais espaço nas pesquisas nacionais, abordando inclusive a relação da remuneração com outros aspectos do ambiente empresarial (Santos \& Silva, 2017).

A presente pesquisa investiga a influência do controle familiar na remuneração de executivos em empresas brasileiras de capital aberto no período de 2010 a 2016. Foram coletados dados do item 13.2 do formulário de referência divulgado por 110 empresas brasileiras de capital aberto (de diversos setores, exceto o financeiro), assim como da base Sistemas de Informações Corporativas, para o período de 2010 a 2016. As empresas foram classificadas quanto a presença da família, e observada a remuneração dos executivos entre empresas familiares e não familiares. Os resultados indicam que a presença da família simultaneamente no controle, na propriedade e na gestão dessas empresas está associada à uma menor remuneração executiva, o que denotaria que tais executivos têm outro direcionador de motivação nestas organizações.

\section{REFERENCIAL TEÓRICO}

Embora não exista um conceito único sobre o que representa uma empresa familiar, sabe-se que nessas empresas a família além de participar de forma predominante da propriedade e controle da empresa e ainda estar entre os executivos, influencia a gestão por meio de fatores emocionais (Berrone, Cruz \& Gomez-Mejia, 2012; File \& Prince, 1996; Gomez-Mejia, Cruz, Berrone \& De Castro, 2011). Dentre esses fatores emocionais, o sentimento de segurança vem da concentração da propriedade e gestão entre os membros da família (File \& Prince, 1996; Chisman, Chua, Pearson \& Barnett, 2012), indicando o monopólio familiar na administração da empresa. Outro fator emocional é a preservação dos negócios no seio da família refere-se à inserção dos membros familiares na gestão, por meio de sucessão familiar (File \& Prince, 1996; Tagiuri \& Davis, 1996). Tais características emocionais de segurança e preservação dos negócios diferenciam as empresas familiares das empresas não familiares (File \& Prince, 1996).

Para Mazzi (2011), os critérios necessários para que uma organização empresarial seja considerada familiar ou não podem variar de forma significativa, dando origem a definições mais amplas ou restritas. Assim, para definir se uma empresa é familiar torna-se fundamental a observação das dimensões que envolvem o ambiente organizacional - o poder, a experiência e a cultura (Mazzi, 2011).

O poder é caracterizado pela forma como a empresa determina suas políticas de governança, propriedade, e o nível de participação da família na administração (Chrisman, Devaraj \& Patel, 2017; Mazzi, 2011; Chisman, Chua, Pearson \& Barnett, 2012). A dimensão da experiência é caracterizada pelas sucessões ocorridas entre os membros familiares, envolvendo a participação de membros da família na gestão e no conselho administrativo, mantendo a perpetuidade dos negócios (Mazzi, 2011; Memili, Misra, Chang \& Chisman, 2013). 
Por fim, a dimensão de cultura organizacional enfatiza os valores afetivos relacionados aos negócios e ao compromisso da família com a empresa (Mazzi, 2011). A cultura também envolve a preservação da riqueza socioemocional, pelo valor afetivo da família para com a empresa e outros familiares, e também o anseio da família para a sucessão dos negócios entre os membros familiares (Memili, Misra, Chang \& Chisman, 2013; Silva, 2015).

Pode-se afirmar, portanto que a empresa familiar possui o envolvimento da família na estrutura de propriedade, controle e gestão, objetivando não somente benefícios econômicos, como a manutenção da riqueza no seio da família, mas também benefícios não econômicos, como a perpetuidade dos negócios entre os membros familiares, e a preservação da riqueza socioemocional vinculados à família, diferentemente das empresas não familiares. Por isso, em empresas familiares o planejamento, a gestão e até mesmo a remuneração de seus funcionários podem ser definidos de maneira distinta, quando comparadas a empresas não familiares.

A remuneração é a recompensa monetária fornecida pela organização em contrapartida ao trabalho desempenhado pelos indivíduos que ela tem à disposição (Baker, Jensen \& Murphy, 1988; Dutra \& Hipólito, 2012). Em geral, os principais componentes que envolvem a remuneração podem ser definidos como: (i) salário fixo; (ii) bônus variável; (iii) salário acrescido de bônus; (iv) opção por participação de ações; (v) benefícios indiretos; e (vi) planos de poupança. A soma de todas essas variáveis, ou parte delas, pode ser definida como a remuneração total a ser recebida (Murphy, 1985).

A remuneração pode influenciar positivamente o comportamento dos colaboradores em prol dos interesses da empresa, que normalmente referem-se à perpetuidade da organização e a maximização dos resultados (Chênevert \& Tremblay, 2009). É um mecanismo capaz de atrair, reter e motivar diversos níveis da organização e, consequentemente, proporcionar benefícios para a empresa, incluindo a eficiência e o sucesso nos negócios (Balkin, Gomes-Mejia, 1987; Bender \& Moir, 2006). Assim, a remuneração representa uma das principais ferramentas para a gestão das empresas. A remuneração variável atua como direcionadora do alinhamento de interesses entre proprietário e executivo, permitindo a alocação de esforços para o alcance dos objetivos (Beuren, Silva \& Mazzioni, 2014; Silva, 2015).

Em empresas familiares os objetivos organizacionais estão centrados nos interesses da família, e isso induz a criação de uma riqueza socioemocional, envolvendo a preservação dos valores da família: harmonia e reputação, o que tende a influenciar a remuneração dos executivos (Gómez-Mejía et al., 2007). A riqueza socioemocional representa os valores afetivos dos membros da família com a organização, a relação emocional e o desejo de perpetuidade do negócio entre os membros familiares (Memili, Misra, Chang \& Chrisman, 2013). Assim, a propensão para a remuneração de executivos tende a ser fornecida em menor nível nas empresas familiares. não familiares.

H1: Empresas familiares tendem a remunerar menos seus executivos, quando comparadas as empresas

Quando a autonomia das famílias no controle assume níveis elevados, a concessão de incentivos tende a ser menor, pois estes planos de incentivos podem empoderar os executivos e influenciar a família de discrição para agir conforme seus interesses (Memili, Misra, Chang \& Chisman, 2013). Pressupõe-se, portanto, que nas empresas familiares o processo de avaliação é mais arbitrário, o que pode sugerir que a discricionariedade no fornecimento de incentivos tenha um efeito redutor (Speckbacher \& Wentgens, 2012; Silva, 2015).

Além disso, quando predomina a influência da família em termos de propriedade e gestão a tendência é que para a preservação da riqueza socioemocional, os incentivos de remuneração aos executivos sejam menores (Memili, Misra, Chang \& Chisman, 2013), pois a gestão e a propriedade podem coincidir, pelo menos em parte, o que levaria ao menor uso de incentivos para o alinhamento de interesses (Gomez-Mejia, Larraza-Kintana \& Makri, 2003).

H2: Empresas familiares tendem a utilizar menor proporção de incentivo variável em seus planos de incentivos aos executivos, quando comparadas as empresas não familiares.

\section{DADOS E MÉTODO}

Os dados necessários para a realização deste estudo foram obtidos por meio da leitura do item 13.2 do formulário de referência das empresas brasileiras listadas na B3, divulgados na Comissão de Valores Mobiliários (CVM) e, também, extraídos do banco de dados do software SInC - Sistemas de Informações Corporativas, para o período de 2010 a 2016. A amostra é composta por 110 empresas, conforme mostra a Tabela 1. 
Foram excluídas da amostra todas as companhias que durante o período analisado, não divulgaram as informações necessárias para esta pesquisa. Além disso, empresas do setor financeiro não foram incluídas, pois estas instituições são conhecidas por remunerarem seus executivos com os mais altos salários dentre as companhias, em função dos riscos assumidos por essas organizações (Aduda, 2011).

Tabela 1. Análise descritiva das variáveis do estudo

\begin{tabular}{rc}
\hline Setor econômico & Número de empresas \\
\hline Bens industriais & 20 \\
Consumo cíclico & 31 \\
Consumo não cíclico & 7 \\
Materiais básicos & 13 \\
Petróleo, gás e biocombustíveis & 1 \\
Saúde & 6 \\
Tecnologia da informação & 4 \\
Telecomunicações & 3 \\
Utilidade pública & 25 \\
Total & 110 \\
\hline
\end{tabular}

Fonte: Elaborado pelos autores.

Nota: Setores econômicos foram extraídos da B3.

As empresas contidas na amostra foram classificadas em empresas familiares e empresas não familiares, baseado no controle, no contrato, na propriedade e na gestão que apresentam.O controle familiar foi observado pelo percentual de ações ordinárias em posse dos acionistas controladores. A propriedade familiar foi identificada pelo percentual de participação dos membros familiares como acionistas controladores, no formulário de referência (1 se superior a $15 \%$ das ações ordinárias). A presença da família na gestão foi constatada por meio da presença de seus membros no conselho de administração. As fontes, bem como a diferenciação dos critérios que foram utilizados para a classificação das empresas familiares, estão descritos no Quadro 1. Ressalta-se que neste estudo a empresa foi considerada familiar com a existência da presença da família simultaneamente no controle, na propriedade e na gestão da organização.

\begin{tabular}{rlll}
\hline Critério & \multicolumn{1}{c}{ Descrição } & \multicolumn{1}{c}{ Fonte } & \multicolumn{1}{c}{ Referência } \\
\hline \multirow{2}{*}{ Controle } & $\begin{array}{l}\text { Existência de percentual de } \\
\text { ações ordinárias em posse dos } \\
\text { acionistas controladores. }\end{array}$ & $\begin{array}{l}\text { Formulário de } \\
\text { Referência - Item 12.9 } \\
\text { e 15.1/2 }\end{array}$ & $\begin{array}{l}\text { La Porta; Lopez-De-Silanes } \\
\text { e Shleifer (1999); Martinez e } \\
\text { Ramalho (2014) Silva; Souza e } \\
\text { Klann (2016) }\end{array}$ \\
& $\begin{array}{l}\text { A propriedade familiar foi } \\
\text { considerada no caso de os } \\
\text { membros familiares possuírem } \\
\text { mais que 15\% das ações } \\
\text { Prdinárias. }\end{array}$ & $\begin{array}{l}\text { Formulário de } \\
\text { Referência - Item 12.9 } \\
\text { e 15.1/2 }\end{array}$ & $\begin{array}{l}\text { La Porta; Lopez-De-Silanes; } \\
\text { Shleifer (1999); Martinez; Ramalho } \\
\text { (2014) Silva; Souza; Klann (2016) }\end{array}$ \\
$\begin{array}{l}\text { Se algum membro da família } \\
\text { faz parte do Conselho de } \\
\text { Administração. }\end{array}$ & $\begin{array}{l}\text { Formulário de } \\
\text { Referência - Item 12.9 } \\
\text { e 12.6/8 }\end{array}$ & $\begin{array}{l}\text { La Porta; Lopez-De-Silanes; } \\
\text { Shleifer (1999); Martinez; Ramalho } \\
\text { (2014) Silva; Souza; Klann (2016) }\end{array}$ \\
\hline
\end{tabular}

Quadro 1. Critérios para classificação das empresas familiares

Fonte: Elaborado pelos autores.

Nota: As empresas são consideradas "familiares" se os 3 critérios são atendidos simultaneamente.

A menor remuneração total média fornecida aos executivos, como mostra a Tabela 2, foi em torno de 25 mil reais, e refere-se a empresa ENERGISA S.A., caracterizada como uma empresa não familiar dentro do setor de utilidade pública. Em contrapartida, a maior remuneração total média concedida aos executivos foi de 25,312 milhões, paga pela VALE S.A, caracterizada como uma empresa não familiar no setor de materiais básicos da B3. 
Tabela 2. Estatísticas descritivas das variáveis quantitativas

\begin{tabular}{|c|c|c|c|c|c|c|c|}
\hline Variável & Obs. & Média & Desvio-padrão & Mín. & Máx. & $\begin{array}{l}\text { Empresas } \\
\text { familiares }\end{array}$ & $\begin{array}{c}\text { Empresas não } \\
\text { familiares }\end{array}$ \\
\hline Empresa Familiar $(=1)$ & 770 & 0,37 & 0,48 & 0,00 & 1,00 & 41,00 & 69,00 \\
\hline Remuneração total média (ano) & 770 & 2,30 & 2,35 & 25,03 & 25,31 & 1,73 & 2,63 \\
\hline Remuneração variável média (ano) & 770 & 1,10 & 1,47 & 1,72 & 17,99 & 0,77 & 1,31 \\
\hline Proporção remuneração variável & 770 & 0,40 & 0,26 & 0,00 & 4,58 & 0,39 & 0,43 \\
\hline Avaliação desempenho individual & 770 & 0,70 & 0,46 & 0,00 & 1,00 & 0,62 & 0,73 \\
\hline Avaliação desempenho organizacional & 770 & 0,98 & 0,15 & 0,00 & 1,00 & 0,99 & 0,96 \\
\hline Avaliação financeira & 770 & 0,98 & 0,15 & 0,00 & 1,00 & 0,99 & 0,96 \\
\hline Avaliação não financeira & 770 & 0,65 & 0,48 & 0,00 & 1,00 & 0,59 & 0,68 \\
\hline Avaliação desempenho longo prazo & 770 & 0,62 & 0,49 & 0,00 & 1,00 & 0,54 & 0,60 \\
\hline Avaliação desempenho curto prazo & 770 & 0,96 & 0,20 & 0,00 & 1,00 & 0,97 & 0,95 \\
\hline Tamanho (venda líquidas milhões de R\$) & 770 & 7,23 & 13,28 & 941,00 & 101,49 & 3,810 & 9,26 \\
\hline Número de executivos & 770 & 6,13 & 3,03 & 2,00 & 31,83 & 6,05 & 6,18 \\
\hline
\end{tabular}

Fonte: Elaborado pelos autores. 
As variáveis dependentes referem-se à remuneração total média anual, remuneração variável média anual e proporção da remuneração variável despendida à Diretoria Estatutária no período analisado. Para o cálculo da remuneração total média utilizou-se o total de remuneração (fixa e variável) fornecida no ano, dividida pela quantidade de membros da diretoria. A remuneração variável média calculou-se por meio da soma da remuneração por Bônus, participação nos resultados, participação em reuniões, comissões e Remuneração baseada em ações e posteriormente dividida pela quantidade de membros da Diretoria para cada ano da amostra. Valores mínimos como R \$ 1,7 mil/ano são possíveis por se tratar de remuneração variável. Os valores médios identificados, total pago à diretoria estatutária dividido pelo número de diretores elimina as diferenças salarias observáveis entre diretores de uma mesma empresa, pois trabalha-se com a média na empresa. Mas mantém a comparabilidade entre empresas. Por fim a variável de Proporção da Remuneração variável refere-se à proporção do total da remuneração varável média pelo total da remuneração total média despendida.

A variável independente de empresa familiar foi adicionada ao modelo por meio da classificação de presença da família simultaneamente no controle, propriedade e gestão da empresa (Quadro 1) para que fosse testada a relação entre a remuneração dos executivos nas empresas familiares versus empresas não familiares. Adicionalmente foram utilizadas outras variáveis explicativas de uso de indicadores para avaliação de desempenho de diversas naturezas ( 1 presente, 0 não presente na empresa) entre eles: individual, organizacional, financeiro, não financeiro, longo prazo e curto prazo. A presença da avaliação foi detectada na leitura do formulário de referência, em que a empresa afirma o uso destes indicadores para atribuição de remuneração à Diretoria Estatutária na empresa.

Para que fosse possível reduzir heterogeneidade da amostra, utilizou-se as variáveis de controle de total de vendas líquidas na empresa e também a quantidade de executivos que compõe a Diretoria estatutária para cada ano da amostra.

\section{RESULTADOS E DISCUSSÃO}

Com relação a remuneração variável média despendida o menor valor fornecido foi de 1,7 mil reais no ano de 2013, e refere-se também a empresa ENERGISA S.A. Em contrapartida, o maior valor foi em torno de $\$$ 17,994 milhões no ano de 2014, pago pela empresa ESTÁCIO PARTICIPAÇÕES S.A, pertencente ao setor de consumo cíclico da B3. Nota-se que, tanto o menor quanto o maior valor de remuneração variável fornecida aos executivos foram apresentados por empresas não familiares.

É importante ressaltar que, conforme o item 13.2 do formulário de referência, o número de executivos da amostra pode não ser apresentado por números inteiros, devido à rotatividade de executivos no período. Por isso, caso algum executivo se desligue da empresa ao longo do ano e não seja reposto, a quantidade é informada no formulário de referência proporcionalmente ao período de permanência na empresa. A análise descritiva das variáveis de remuneração total média e de remuneração variável é apresentada na Tabela 3.

Tabela 3. Análise da remuneração média anual de executivos por tipo de empresa e ano (milhares R\$)

\begin{tabular}{rcccccccc}
\hline Remuneração (anual) & Empresas & $\mathbf{2 0 1 0}$ & $\mathbf{2 0 1 1}$ & $\mathbf{2 0 1 2}$ & $\mathbf{2 0 1 3}$ & $\mathbf{2 0 1 4}$ & $\mathbf{2 0 1 5}$ & $\mathbf{2 0 1 6}$ \\
\hline \multirow{2}{*}{ Total média } & Familiares & 1.224 & 1.467 & 1.587 & 1.873 & 1.784 & 1.883 & 2.188 \\
& Não familiares & 2.134 & 2.433 & 2.281 & 2.466 & 2.741 & 3.157 & 3.445 \\
\cline { 2 - 9 } Variável média & Familiares & 583 & 688 & 719 & 897 & 729 & 790 & 988 \\
& Não familiares & 1.166 & 1.130 & 1.184 & 1.246 & 1.561 & 1.507 & 1.726 \\
\hline
\end{tabular}

Fonte: Elaborado pelos autores.

Para as empresas não familiares, a maior e a menor remuneração total recebida foi de 3,4 milhões em 2016 e 1,2 milhão em 2010, respectivamente. Durante o período analisado, as empresas não familiares também forneceram remuneração variável em maior proporção para seus executivos, quando comparadas as empresas familiares. Ou seja, enquanto em empresas não familiares a remuneração variável foi em média de 1,7 milhões em 2016, nas empresas familiares o valor médio recebido foi de 988 mil, o que indica que as empresas familiares tendem a remunerar menos os executivos de forma variável quando comparadas às empresas não familiares. 
A correlação de Sperman (Apêndice A) mostra correlação negativa e significante entre a remuneração variável dos executivos e a dummy de empresas familiares (-0.134 p-valor $>0.00)$. No teste de média de MannWhitney (não apresentados) foi observado que as empresas familiares remuneram seus executivos em menor proporção do que as empresas não familiares da amostra, tanto com relação a remuneração total quanto a variável.

Memili, Misra, Chang e Chisman (2013) investigaram se a influência da riqueza sócio emocional no ambiente da empresa familiar determina limites de remuneração variável aos executivos. Os resultados indicaram que a existência de metas tradicionais para conservar a influência da família pode impactar o fornecimento de remuneração variável aos executivos.

Para detectar a influência da família na remuneração dos executivos seguiu uma estrutura de testes recomendados por Fávero, Belfiore, Takamatsu e Suzart (2014); Fávero e Belfiore (2017) e; Hilbe (2009). Comparando efeitos fixos e efeitos aleatórios o teste de Hausman (não apresentados) indica que o modelo efeitos aleatórios é mais adequado, apresentando resultado significativo nos modelos de remuneração total média (Chi2=9.38; Prob Chi2>0.3110), para o modelo de remuneração variável média (Chi2=8.78; Prob Chi2>0.3610), e para o modelo de proporção de remuneração variável (Chi2=9.75; Prob Chi2>0.2830). Apresenta-se na Tabela 4 a estimação para efeitos aleatórios, com correção para auto correlação de resíduos e correção para erros-padrões robustos.

Empresas familiares, possuem menor remuneração total e variável, e uma menor proporção de remuneração variável nos seus sistemas de incentivo. Esses achados corroboram os resultados de Gomez-Mejia, LarrazaKintana e Makri (2003), ao destacar que os executivos das empresas familiares recebem menos remuneração total do que os executivos das empresas não familiares, à medida que a concentração de propriedade familiar na empresa aumenta, devido a manutenção da riqueza entre os membros da família. McConaughy (2000) destaca que os incentivos para os executivos nas empresas familiares são menores, devido ao alinhamento de interesses da família.

A ocorrência desse resultado encontra amparo na pesquisa de Chen; Hsu; Chen (2014), os quais verificaram que as empresas controladas pela família oferecem uma menor proporção de remuneração variável para os executivos, devido à relação de agência menos predominante em empresas familiares. Gomez-Mejia, Larraza-Kintana \& Makri (2003) não analisam de forma comparativa a remuneração dos executivos familiares versus não familiares e como o vínculo familiar tende a proteger o executivo. Além disso, os autores evidenciaram que a remuneração dos executivos familiares tende a ser mais isolada do risco de mercado.

A hipótese tinha como pressuposto que nas empresas familiares, devido aos objetivos e metas organizacionais estarem centradas no interesse da família, isso proporcionaria menor remuneração aos executivos da diretoria estatutária (Gomez-Mejia, Haynes, Núñez-Nickel, Jacobson \& Moyano-Fuentes, 2007). O que se justifica devido ao fato de que, quando a gestão e a propriedade das empresas familiares coincidem pelos menos em parte, tende a influenciar o fornecimento de remuneração aos executivos (Chrisman; Memili, Chang \& Misra, 2014). 
Tabela 4. Resultados da estimação com efeitos aleatórios e auto correlação de resíduos e erros padrões robustos (para modelos de remuneração em empresas familiares)

\begin{tabular}{|c|c|c|c|}
\hline & $\begin{array}{c}\text { Remuneração total } \\
\text { média } \\
\text { Auto-correlação }\end{array}$ & $\begin{array}{c}\text { Remuneração variável } \\
\text { média } \\
\text { Robust }\end{array}$ & $\begin{array}{c}\text { Proporção de } \\
\text { remuneração variável } \\
\text { Robust }\end{array}$ \\
\hline \multirow{2}{*}{ Empresas familiares } & $-1110758 * * *$ & $-784102,1 * * *$ & $-0,1017 * *$ \\
\hline & (319389) & $(224728,1)$ & $(0,0418)$ \\
\hline \multirow{2}{*}{ Avaliação de desempenho individual } & $-218366,8$ & 10242,76 & 0,0288 \\
\hline & $(254984,2)$ & $(134372,3)$ & $(0,0301)$ \\
\hline \multirow{2}{*}{ Avaliação de desempenho organizacional } & 742703,8 & $911879,7 * * *$ & $0,0678 * *$ \\
\hline & $(964345,7)$ & $(163615)$ & $(0,0338)$ \\
\hline \multirow{2}{*}{ Avaliação de desempenho financeiro } & -572672 & $-455151,8^{* *}$ & $-0,0007$ \\
\hline & $(966054)$ & $(220046,1)$ & $(0,0448)$ \\
\hline \multirow{2}{*}{ Avaliação de desempenho não financeiro } & $480700,9 * *$ & 121453 & $-0,0354$ \\
\hline & $(234063,9)$ & $(145269,9)$ & $(0,0277)$ \\
\hline \multirow{2}{*}{ Avaliação de desempenho a longo prazo } & $974102,2 * * *$ & $506971,2 * * *$ & $0,0577 * *$ \\
\hline & $(208517)$ & $(125732,4)$ & $(0,0257)$ \\
\hline \multirow{2}{*}{ Avaliação de desempenho a curto prazo } & $-741938,3$ & $-692673,2 * *$ & $-0,1011$ \\
\hline & $(530010,4)$ & $(311697,7)$ & $(0,0672)$ \\
\hline \multirow{2}{*}{ Ln Tamanho (Vendas Liquidas) } & $384442,2 * * *$ & $167442,9 * *$ & 0,0170 \\
\hline & $(78334,49)$ & $(61710,48)$ & $(0,0109)$ \\
\hline \multirow{2}{*}{ Número de executivos } & $-142169,9 * * *$ & $-46103,76^{*}$ & $-0,000$ \\
\hline & $(35285,5)$ & $(25720,64)$ & $(0,0036)$ \\
\hline $\mathrm{R} 2$ & 0,4878 & 0,4096 & 0,2796 \\
\hline Obs. & 770 & 770 & 770 \\
\hline Grupos & 110 & 110 & 110 \\
\hline \multicolumn{4}{|c|}{ Setores econômicos } \\
\hline \multirow{8}{*}{ Petróleo, gás e biocombustíveis } & $277675,1 * *$ & 358141,6 & 0,0661 \\
\hline & $(416675,9)$ & $(293026,5)$ & $(0,0524)$ \\
\hline & $1761544 * *$ & $888922,9 * *$ & 0,0149 \\
\hline & $(619517,9)$ & $(427553,2)$ & $(0,0537)$ \\
\hline & $1338964 * * *$ & $675973 *$ & 0,0639 \\
\hline & $(504594)$ & $(355311,1)$ & $(0,0589)$ \\
\hline & 2507200 & $498242,1^{*}$ & 0,110 \\
\hline & $(1423785)$ & $(259437,5)$ & $(0,0470)$ \\
\hline \multirow{2}{*}{ Saúde } & $-226639,1$ & $-149405,2$ & $-0,0010$ \\
\hline & $(644996,9)$ & $(312725,7)$ & $(0,0643)$ \\
\hline \multirow{2}{*}{ Tec. da informação } & 360654,8 & $-55707,38$ & $-0,0416$ \\
\hline & $(785465,4)$ & $(312058,3)$ & $(0,0860)$ \\
\hline \multirow{2}{*}{ Telecomunicações } & 1310630 & $-222387,5$ & $-0,1120 * *$ \\
\hline & $(861752,6)$ & $(330219,8)$ & $(0,0433)$ \\
\hline \multirow{2}{*}{ Utilidade pública } & $-997642,3 * *$ & $-642844,8 * *$ & $-0,1251 * *$ \\
\hline & $(428975,8)$ & $(263666,1)$ & $(0,0441)$ \\
\hline
\end{tabular}

Fonte: Elaborado pelos autores.

Nota: O erro padrão dos coeficientes e mostrado entre parênteses. *** e*** indicam significância aos níveis de $10 \%, 5 \%$ e $1 \%$ respectivamente. Os resultados do Teste de Wooldridge indicam que a auto correlação não se mostrou um problema para os modelos de remuneração variável média e de proporção da remuneração variável. Assim, aceita-se a hipótese nula de que não existe auto correlação nestes modelos econométricos, dado que o p-valor do modelo de remuneração variável média (0.6120) e do modelo de proporção da remuneração variável (0.5843) é maior que 0.05 , indicando a não existência de auto correlação entre os resíduos da regressão. Em contrapartida, o modelo de remuneração total média apresentou problemas de auto correlação com p-valor de 0.0405, indicando a presença de auto correlação entre os resíduos da regressão. Para testar a presença de heterocedasticidade foi realizado o estimador da máxima verossimilhança nos resíduos das regressões em painel. Os resultados do teste evidenciados na Tabela 4, apontam que, para os modelos de remuneração total média, remuneração variável média e proporção da remuneração variável, os erros não são homocedásticos, prevalecendo a presença de heteroscedasticidade, indicando que a variância condicional do erro é constante em t, e por isso todos os modelos serão estimados com erro padrão robusto (Fávero et al., 2014) 
Em relação a $\mathrm{H} 2$, os resultados encontrados sugerem, que as empresas familiares brasileiras utilizam menos a parcela variável da remuneração quando comparadas as empresas não familiares. Um fator predominante no ambiente de uma empresa familiar, o alinhamento de interesses da família envolve a utilização de metas mais tradicionais e econômicas afetando diretamente o sistema de controle gerencial e o desempenho de sistemas de incentivos aos executivos (Mc Conaughy, 2000; Memili, Misra, Chang \& Chisman, 2013). Além disso, a autonomia da família na empresa reduz a oferta de incentivos aos executivos (Memili, Misra, Chang \& Chisman, 2013).

\section{CONCLUSÃO}

O objetivo deste estudo foi verificar se a remuneração total e variável é menor nas empresas familiares, quando comparadas às empresas não familiares brasileiras. As pesquisas internacionais afirmam que as empresas familiares tendem a dispender menos remuneração aos executivos do que as empresas não familiares, devido a relação de agencia menos predominante neste tipo de organização.

Em decorrência da análise dos resultados, verificou-se a influência da família na remuneração dos executivos, seja por remuneração total ou remuneração variável e pela menor proporção de remuneração variável na remuneração executiva. Este achado indica que as empresas familiares brasileiras utilizam menos a remuneração executiva como elemento de alinhamento de interesses, quando comparadas as empresas não familiares. Isso pode ser relevante e deve ser analisado durante o desenho e configuração dos sistemas de avaliação de desempenho e consequente oferecimento de incentivos aos executivos.

Além disso, a participação da família nas decisões da organização pode fazer com que a necessidade de alinhamento de interesses ocorra de forma mais natural. Tais reflexões podem ser de interesse de profissionais responsáveis pela configuração dos elementos de controle, avaliação de desempenho e recompensa, que podem considerar que mesmo em grandes organizações com estruturas complexas, o controle e a presença da família na gestão pode suscitar uma substituição da recompensa pecuniária por fontes alternativas de alinhamento de interesses.

\section{REFERÊNCIAS}

Aduda, J. (2011). The relationship between executive compensation and firm performance in the Kenyan banking sector. Journal of Accounting and Taxation, 3(6), 130. DOI: https://doi.org/10.5897/JAT2018.0318

Baker, G. P., Jensen, M. C., \& Murphy, K. J. (1988). Compensation and incentives: Practice vs. theory. The journal of Finance, 43(3), 593-616. DOI: https://doi.org/10.2307/2328185

Balkin, D. B., \& Gomez-Mejia, L. R. (1987). Toward a contingency theory of compensation strategy. Strategic Management Journal, 8(2), 169-182.

Bender, R., \& Moir, L. (2006). Does 'best practice'in setting executive pay in the UK encourage 'good'behaviour?. Journal of Business Ethics, 67(1), 75-91. DOI: https://doi.org/10.1007/s10551-006-9006-8

Berrone, P., Cruz, C., \& Gomez-Mejia, L. R. (2012). Socioemotional wealth in family firms: Theoretical dimensions, assessment approaches, and agenda for future research. Family Business Review, 25(3), 258279. DOI: https://doi.org/10.1177/0894486511435355

Beuren, I. M., Zanievicz da Silva, M., \& Mazzioni, S. (2014). Remuneração dos executivos versus desempenho das empresas. Revista de Administração FACES Journal, 13(2).

Chen, C. J., Hsu, C. Y., \& Chen, Y. L. (2014). The impact of family control on the top management compensation mix and incentive orientation. International Review of Economics \& Finance, 32, 29-46. DOI: https://doi. org/10.1016/j.iref.2014.01.005

Chenevert, D., \& Tremblay, M. (2009). Fits in strategic human resource management and methodological challenge: Empirical evidence of influence of empowerment and compensation practices on human resource performance in Canadian firms. The International Journal of Human Resource Management, 20(4), 738-770. DOI: https://doi.org/10.1080/09585190902770547

Chrisman, J. J., Chua, J. H., Pearson, A. W., \& Barnett, T. (2012). Family involvement, family influence, and family-centered non-economic goals in small firms. Entrepreneurship theory and practice, 36(2), 267-293. DOI: https://doi.org/10.1111/j.1540-6520.2010.00407.x 
Chrisman, J. J., Devaraj, S., \& Patel, P. C. (2017). The impact of incentive compensation on labor productivity in family and nonfamily firms. Family Business Review, 30(2), 119-136. DOI: https://doi. org/10.1177/0894486517690052

Dutra, J. S., \& Hipólito, J. A. M. (2012). Remuneração e recompensas. São Paulo: Atlas.

Fávero, L. P., Belfiore, P., Takamatsu, R. T., \& Suzart, J. (2014). Métodos quantitativos com Stata. Elselvier, 1a edição. Rio de Janeiro-RJ, 131-142.

Fávero, L. P., \& Belfiore, P. (2017). Manual de análise de dados: estatística e modelagem multivariada com Excel $\AA$, SPSS ${ }^{\text {e Stata }}$ . Elsevier Brasil

File, K. M., \& Prince, R. A. (1996). A psychographic segmentation of industrial family businesses. Industrial Marketing Management, 25(3), 223-234. DOI: https://doi.org/10.1016/0019-8501(95)00080-1

Gómez-Mejia, L. R., Larraza-Kintana, M., \& Makri, M. (2003). The determinants of executive compensation in family-controlled public corporations. Academy of management journal, 46(2), 226-237. DOI: https:/doi. org/10.2307/30040616

Gómez-Mejía, L. R., Haynes, K. T., Núñez-Nickel, M., Jacobson, K. J., \& Moyano-Fuentes, J. (2007). Socioemotional wealth and business risks in family-controlled firms: Evidence from Spanish olive oil mills. Administrative science quarterly, 52(1), 106-137. DOI: https://doi.org/10.2189/asqu.52.1.106

Gomez-Mejia, L. R., Cruz, C., Berrone, P., \& De Castro, J. (2011). The bind that ties: Socioemotional wealth preservation in family firms. Academy of Management Annals, 5(1), 653-707. DOI: https://doi.org/10.1080/ 19416520.2011 .593320

Holmstrom, B., \& Milgrom, P. (1991). Multitask principal-agent analyses: Incentive contracts, asset ownership, and job design. Journal of Law, Economics, \& Organization, 7, 24-52.

Jensen, M. C., \& Meckling, W. H. (1976). Theory of the firm: Managerial behavior, agency costs and ownership structure. Journal of financial economics, 3(4), 305-360. DOI: https://doi.org/10.1016/0304-405X(76)90026-X

Jensen, M. C., \& Murphy, K. J. (1990). Performance pay and top-management incentives. Journal of political economy, 98(2), 225-264. DOI: http://dx.doi.org/10.2139/ssrn.94009

La Porta, R., Lopez-de-Silanes, F., \& Shleifer, A. (1999). Corporate ownership around the world. The journal of finance, 54(2), 471-517. DOI: https://doi.org/10.1111/0022-1082.00115

Martinez, A. L., \& Ramalho, G. C. (2014). Family Firms and Tax Aggressiveness in Brazil. International Business Research, 7(3), 129. DOI: https://doi.org/10.5539/ibr.v7n3p129

Mazzi, C. (2011). Family business and financial performance: Current state of knowledge and future research challenges. Journal of Family Business Strategy , 2 (3), 166-181. DOI: https://doi.org/10.1016/j. jfbs.2011.07.001

McConaughy, D. L. (2000). Family CEOs vs. nonfamily CEOs in the family-controlled firm: An examination of the level and sensitivity of pay to performance. Family Business Review, 13(2), 121-131. DOI: https://doi. org/10.1111/j.1741-6248.2000.00121.x

Memili, E., Misra, K., Chang, E. P., \& Chrisman, J. J. (2013). The propensity to use incentive compensation for non-family managers in SME family firms. Journal of family business management, 3(1), 62-80. DOI: https:// doi.org/10.1108/20436231311326490

Murphy, K. J. (1985). Corporate performance and managerial remuneration: An empirical analysis. Journal of accounting and economics, 7(1-3), 11-42. DOI: https://doi.org/10.1016/0165-4101(85)90026-6

Murphy, K. J. (2012). Executive compensation: Where we are, and how we got there. Handbook of the Economics of Finance, Chapter 4: 211-356.

Santos, T. R., \& Silva, J. O. (2017). Remuneração de executivos: uma análise dos artigos nacionais e internacionais na última décade. Revista de Gestão, Finanças e Contabilidade, 7(2), 265. DOI: http://dx.doi. org/10.18028/2238-5320/ rgfc.v7n2p265-283

Silva, J. O. (2010). Relação entre a remuneração variável dos gestores e o gerenciamento de resultados nas empresas de capital aberto brasileiras. (Dissertação de mestrado) Mestrado em Ciências ContábeisUniversidade Regional de Blumenau, Blumenau). 
Silva, J. O. D. (2015). Remuneração variável de executivos em empresas familiares brasileiras (Tese de doutorado, Universidade de São Paulo).

Silva, A. da, Souza, T. R. de., \& Klann, R. C. (2016). Tempestividade da informação contábil em empresas familiares brasileiras. RAE-Revista de Administração de Empresas, 56(5). DOI: http://dx.doi.org/10.1590/ s0034-759020160504

Schwartz, Y. (1996). Trabalho e valor. Tempo social, 8(2), 147-158.

Speckbacher, G., \& Wentges, P. (2012). The impact of family control on the use of performance measures in strategic target setting and incentive compensation: A research note. Management Accounting Research, 23(1), 34-46. DOI:10.1016/j.mar.2011.06.002

Tagiuri, R., \& Davis, J. (1996). Bivalent attributes of the family firm. Family business review, 9(2), 199-208. DOI: https://doi.org/10.1111/j.1741-6248.1996.00199.x

Wiseman, R. M., \& Gomez-Mejia, L. R. (1998). A behavioral agency model of managerial risk taking. Academy of management Review, 23(1), 133-153. DOI: https://doi.org/10.2307/259103

\section{Como citar este artigo}

Santos, T. R., \& Silva, J. O. (2018). A influência da família tem algum efeito? Análise da remuneração dos executivos das empresas familiares e não familiares. Revista de Contabilidade e Organizações, 12:e148149. DOI: http://dx.doi.org/10.11606/issn.1982-6486.rco.2018.148149 
APÊNDICE A - Correlação de Spearman

\begin{tabular}{|c|c|c|c|c|c|c|c|c|c|c|c|c|}
\hline Variáveis & (1) & (2) & (3) & (4) & (5) & (6) & (7) & (8) & (9) & (10) & (11) & (12) \\
\hline \multirow{2}{*}{ Remuneração total média (1) } & 1 & & & & & & & & & & & \\
\hline & 0.0000 & & & & & & & & & & & \\
\hline \multirow{2}{*}{ Remuneração variável média (2) } & 0.924 & 1 & & & & & & & & & & \\
\hline & 0.0000 & 0.0000 & & & & & & & & & & \\
\hline \multirow{2}{*}{ Proporção remuneração variável (3) } & 0.545 & 0.793 & 1 & & & & & & & & & \\
\hline & 0.0000 & 0.0000 & 0.0000 & & & & & & & & & \\
\hline \multirow{2}{*}{ Empresa Familiar (4) } & -0.146 & -0.134 & -0.063 & 1 & & & & & & & & \\
\hline & 0.0000 & 0.0002 & 0.0786 & 0.0000 & & & & & & & & \\
\hline \multirow{2}{*}{ Avaliação desempenho individual (5) } & 0.160 & 0.159 & 0.127 & -0.118 & 1 & & & & & & & \\
\hline & 0.0000 & 0.0000 & 0.0004 & 0.0011 & 0.0000 & & & & & & & \\
\hline \multirow{2}{*}{ Avaliação desempenho organizacional (6) } & 0.089 & 0.106 & 0.084 & 0.098 & 0.228 & 1 & & & & & & \\
\hline & 0.0132 & 0.0033 & 0.0202 & 0.0068 & 0.0000 & 0.0000 & & & & & & \\
\hline \multirow{2}{*}{ Avaliação financeira (7) } & 0.064 & 0.076 & 0.057 & 0.102 & 0.235 & 0.913 & 1 & & & & & \\
\hline & 0.0751 & 0.0347 & 0.1121 & 0.0048 & 0.0000 & 0.0000 & 0.0000 & & & & & \\
\hline \multirow{2}{*}{ Avaliação não financeira (8) } & 0.087 & 0.050 & -0.019 & -0.099 & 0.423 & 0.132 & 0.158 & 1 & & & & \\
\hline & 0.0162 & 0.1670 & 0.5946 & 0.0061 & 0.0000 & 0.0002 & 0.0000 & 0.0000 & & & & \\
\hline \multirow{2}{*}{ Avaliação desempenho longo prazo (9) } & 0.393 & 0.413 & 0.319 & 0.041 & 0.303 & 0.193 & 0.163 & 0.057 & 1 & & & \\
\hline & 0.0000 & 0.0000 & 0.0000 & 0.2518 & 0.0000 & 0.0000 & 0.0000 & 0.1152 & 0.0000 & & & \\
\hline \multirow{2}{*}{ Avaliação desempenho curto prazo (10) } & 0.045 & 0.054 & 0.036 & 0.049 & 0.253 & 0.599 & 0.624 & 0.253 & 0.031 & 1 & & \\
\hline & 0.0000 & 0.1361 & 0.3143 & 0.1782 & 0.0000 & 0.0000 & 0.0000 & 0.0000 & 0.3884 & 0.0000 & & \\
\hline \multirow{2}{*}{ Tamanho (venda líquidas) (11) } & 0.381 & 0.338 & 0.170 & 0.125 & 0.091 & 0.121 & 0.149 & 0.074 & 0.182 & -0.275 & 1 & \\
\hline & 0.0000 & 0.0000 & 0.0000 & 0.0000 & 0.0005 & 0.0119 & 0.0008 & 0.0000 & 0.0404 & 0.0000 & 0.0000 & \\
\hline \multirow{2}{*}{ Número de executivos (12) } & 0.049 & 0.074 & 0.096 & 0.149 & 0.004 & 0.019 & 0.129 & 0.194 & 0.090 & -0.080 & 0.401 & 1 \\
\hline & 0.1789 & 0.0397 & 0.0078 & 0.0261 & 0.0000 & 0.9064 & 0.6049 & 0.0003 & 0.0000 & 0.0122 & 0.0000 & 0.0000 \\
\hline
\end{tabular}

Nota: O p-valor é mostrado abaixo do coeficiente de correlação estimado. 